DOI: http://dx.doi.org/10.22483/2177-5796.2017v19n1p111-126

\title{
Conhecendo a licenciatura em Ciências Agrícolas da UFRPE: aspectos da formação de professores
}

\author{
Ramofly Bicalho Santos \\ Ozias Henrique Santos
}

Resumo: Nossa intenção com este trabalho é conhecer os aspectos históricos da formação de professores na L.A Licenciatura em Ciências Agrícolas da Universidade Federal Rural de Pernambuco (UFRPE), através da leitura crítica do Projeto Político Pedagógico. Nosso objetivo principal foi conhecer as bases históricas da formação de professores do ensino agrícola na UFRPE e as concepções dos atores envolvidos nesse processo. Desenvolvemos uma pesquisa bibliográfica e documental utilizando fontes de investigação, legislações, portarias, decretos e referenciais teóricos produzidos sobre tal temática no Brasil. Neste trabalho conhecemos as bases históricas da educação agrícola na UFRPE, em especial, a formação de professores, a constituição da Licenciatura em Ciências Agrícolas e suas demandas de atendimento às Escolas Agrícolas do nordeste brasileiro. Concluímos que a L.A pode estimular a produção de leituras e reflexões que contemplem a formação de educadores/as, respeito às diferenças, valorização da identidade cultural dos sujeitos, individuais e coletivos, através de uma educação inclusiva, questionadora e democrática.

Palavras-chave: Formação docente. Licenciatura em Ciências Agrícolas. Projeto político pedagógico.

\section{Knowing the degree in Agricultural Sciences of UFRPE: from history to teacher training}

\begin{abstract}
Our intention with this work is to know the historical aspects of teacher education in the A - BA in Agricultural Sciences of Federal Rural University of Pernambuco (UFRPE), through a critical reading of the Political Pedagogical Project. Our main objective was to know the historical bases of the training of teachers of agricultural education in UFRPE and the conceptions of the actors involved in this process. We developed a bibliographical and documentary research, using sources of investigation, laws, ordinances, decrees and theoretical references produced on this subject in Brazil. In this work we know the historical bases of agricultural education in UFRPE, in particular, teacher training, the establishment of the Degree in Agricultural Sciences and its demands of attendance to Agricultural Schools of northeastern Brazil. We conclude that L.A can stimulate the production of readings and reflections that contemplate the formation of educators, respect for differences, and valorization of the cultural identity of individual and collective subjects, through an inclusive, questioning and democratic education.
\end{abstract}

Keywords: Teacher education. Degree in Agricultural Sciences. Pedagogical political project.

Quaestio, Sorocaba, SP, v. 19, n. 1, p. 111-126, abr. 2017. 


\section{Introdução}

O objetivo principal deste artigo é conhecer os aspectos históricos da formação de professores do ensino agrícola na L.A - Licenciatura em Ciências Agrícolas da UFRPE Universidade Federal Rural de Pernambuco, atrelados aos fatores culturais, políticos e sociais que influenciam as diferentes etapas e processos históricos da produção crítica do conhecimento. Entendemos que a formação docente e as transformações educacionais na primeira década do século XXI podem ser vistas como possibilidades de expressão da gestão democrática e emancipatória. Ela incorpora debates e processos de ensino-aprendizagens autônomos na consolidação das escolas agrícolas do nordeste brasileiro, tendo como preocupação o respeito às diferenças sociais, culturais e religiosas.

Este texto mostra ainda os primeiros resultados da Dissertação de Mestrado em Educação defendida no PPGEA - Programa de Pós-Graduação em Educação Agrícola da UFRRJ Universidade Federal Rural do Rio de Janeiro. Uma das nossas preocupações foi conhecer os princípios políticos e pedagógicos da Licenciatura em Ciências Agrícolas na UFRPE, suas bandeiras de lutas e projetos emancipadores, considerando os seguintes desafios: formação política dos educadores e educandos, trabalho coletivo, valorização das histórias de vida e as possíveis articulações entre saberes históricos e educação popular.

O Ensino Agrícola no Brasil foi iniciado no Centro de Pesquisas Jardim Botânico, também conhecido como Horto Real. No entanto, aparece com mais ênfase através da implantação do curso de agricultura, no Estado da Bahia, em 25 de junho de 1812, a pedido de D. João. Todavia, é com a promulgação do Decreto 8.319 de outubro de 1910 que o ensino agrícola é organizado e várias instituições são criadas para tal feito. A Escola Superior de Agricultura e Veterinária localizada no Rio de Janeiro é a mais conhecida. Já em Pernambuco, os primeiros passos do Ensino Agrícola foi com a implantação do "Orphanato Izabel” em 1874, no município de Palmares, criado pelo Barão de Lucena. Este estabelecimento tinha como objetivo recolher jovens abandonados e dar-lhes os conhecimentos agrícolas. Foi o primeiro estabelecimento a oferecer ensino prático de agricultura no Estado de Pernambuco. Em 1894 o "Orphanato Izabel” foi transformado em Escola Industrial Agrícola Frei Caneca, oferecendo dois cursos: um preliminar de estudos preparatórios em três anos e o outro profissional com ênfase em estudos técnicos e duração de cinco anos. 
Além das Instituições acima citadas, em 1911 foi criada, em Pernambuco, a Escola Média de Agricultura no município de Jaboatão, com o intuito de formar profissionais capazes de administrar, organizar e explorar estabelecimentos agrícolas. Os estudos superiores ficaram sob a responsabilidade da Escola Superior de Agricultura e Medicina Veterinária de São Bento ESAMVSB, fundada no dia 03 de novembro de 1912, em Olinda. Esta instituição, após inúmeras mudanças ao longo de sua história, deu origem à atual Universidade Federal Rural de Pernambuco (ARAÚJO, 2013).

Neste artigo, utilizamos a metodologia da pesquisa qualitativa, dialogando com os princípios defendidos por (MINAYO, 1994). Nosso campo exploratório teve como principal finalidade a estreita aproximação com a realidade, combinando teoria, dados e aprofundamento de conceitos, a partir de levantamento bibliográfico, documental e realização de entrevistas não padronizadas (GIL, 1999). Nessa conjuntura, procuramos conhecer historicamente a Universidade Federal Rural de Pernambuco, em especial, a formação de professores agrícolas e a Licenciatura em Ciências Agrícolas, segundo o Projeto Político Pedagógico do curso.

\section{Contextualizando a pesquisa: a Universidade Federal Rural de Pernambuco}

A Universidade Federal Rural de Pernambuco tem como instituição de origem a Escola Superior de Agricultura e Medicina Veterinária de São Bento - ESAMVSB, fundada no dia 03 de novembro de 1912, em Olinda, mais especificamente, no Mosteiro de São Bento. As primeiras aulas iniciaram apenas no dia 01 de fevereiro de 1914, contemplando o ensino agrícola e veterinário. Os monges beneditinos, responsáveis pela administração das aulas, foram, inclusive, enviados para Europa, com o intuito de se especializarem no magistério superior em agricultura e veterinária. No entanto, neste momento inicial de formação, muitos alemães especialistas nas Ciências Agrárias foram contratados por um período de três anos. 
Figura 1 - Hospital Veterinário da Escola Superior de Agricultura e Medicina Veterinária de São Bento



Fonte: LEÃO, R. S. C. (Org.). Memorial fotográfico da UFRPE - o livro dos 100 anos. Pernambuco: UFRPE, 2013.

Observando algumas dificuldades iniciais de funcionamento em relação às atividades práticas dos alunos, os beneditinos responsáveis pela ESAMVSB resolveram transferir a Escola de Agricultura para o Engenho São Bento, localizado a oito quilômetros da Estação Tapera, Estrada de Ferro Central de Pernambuco, município de São Lourenço da Mata. Essa transferência foi realizada no dia 07 de janeiro de 1917 e as aulas iniciaram no dia 03 de março do mesmo ano. Foi também em 1917 que a ESAMVSB conferiu os primeiros graus de médicos veterinários e engenheiros agrônomos. O farmacêutico Dionisyo Meili, formado na Faculdade de Medicina da Bahia, entrou como portador de diploma, obtendo dispensa em várias disciplinas no curso de Medicina Veterinária. Ele foi o primeiro aluno a concluir um curso na ESAMVSB e o primeiro médico veterinário formado e diplomado no país, em 13 de novembro de 1915. No dia 11 de janeiro de 1917 formou-se a primeira turma de médicos veterinários do Estado de Pernambuco. Em 1918, a instituição conseguiu seu registro perante o Ministério da Agricultura. Do ano de 1914 até 1923 a Escola de Agricultura diplomou 23 engenheiros agrônomos. A Escola de Medicina Veterinária, 18 médicos veterinários. No entanto, a Escola de Medicina Veterinária, após a transferência da Escola de Agricultura para o município de São Lourenço da Mata, teve sua procura bastante reduzida e acabou fechando no dia 29 de janeiro de 1926. 
Em 1936, a Escola Superior de Agricultura de São Bento, em função do processo de estadualização, passou a se chamar Escola Superior de Agricultura de Pernambuco. O ensino superior agrícola em Pernambuco, após 25 anos dirigidos pelos beneditinos, seria organizado pelo governo do Estado. Em 1938, a Escola Superior de Agricultura de Pernambuco, em funcionamento no Engenho de São Bento, foi transferida para a localidade de Pedra Mole, atual bairro Dois Irmãos, município do Recife, enquadrando-se nos dispositivos legais propostos pelo Ministério da Agricultura, Indústria e Comércio. Após uma série de equiparações, a Escola Superior de Agricultura de Pernambuco passou a se chamar Universidade Rural de Pernambuco, em 24 de julho de 1947. No ano de 1955 a instituição é federalizada através da lei no .2 .524 . Em 1967, a partir do decreto federal de $\mathrm{n}^{\circ}$. 60.731, oficialmente, ganha o nome de Universidade Federal Rural de Pernambuco (ARAÚJO, 2013).

\section{A formação docente e a educação agrícola na UFRPE: contexto histórico}

A formação docente agrícola na UFRPE - Universidade Federal Rural de Pernambuco teve início em 19 de novembro de 1965 num convênio com a SUDENE - Superintendência de Desenvolvimento do Nordeste e o Ministério da Agricultura, criando, inclusive, o Centro Regional de Educação Técnico-Agrícola - CRETA. O CRETA desenvolvia várias atividades, com destaque para o encontro de diretores dos Colégios Agrícolas do Nordeste. Tais encontros tinham a intenção de dialogar acerca da formação de professores do ensino agrícola.

Em 1969 a UFRPE vivenciou um processo de reestruturação e o CRETA passou a se chamar CFTPA - Centro de Formação e Treinamento de Professores Agrícolas. Em 1975, a partir de uma nova reestruturação, foi substituído pelo Departamento de Educação. Em 1971 foi elaborado o primeiro curso de formação pedagógica para Licenciatura em Ciências Agrícolas, em parceria com a SUDENE, tendo como base o Parecer 111/71 e a Resolução 09/69. O objetivo principal desse curso era habilitar e qualificar professores agrícolas em exercício nas Escolas Agrotécnicas do Nordeste. 
Figura 2 - Participantes do Primeiro Encontro de Diretores dos Colégios Agrícolas do Nordeste. UFRPE. 27-31/03/1967.

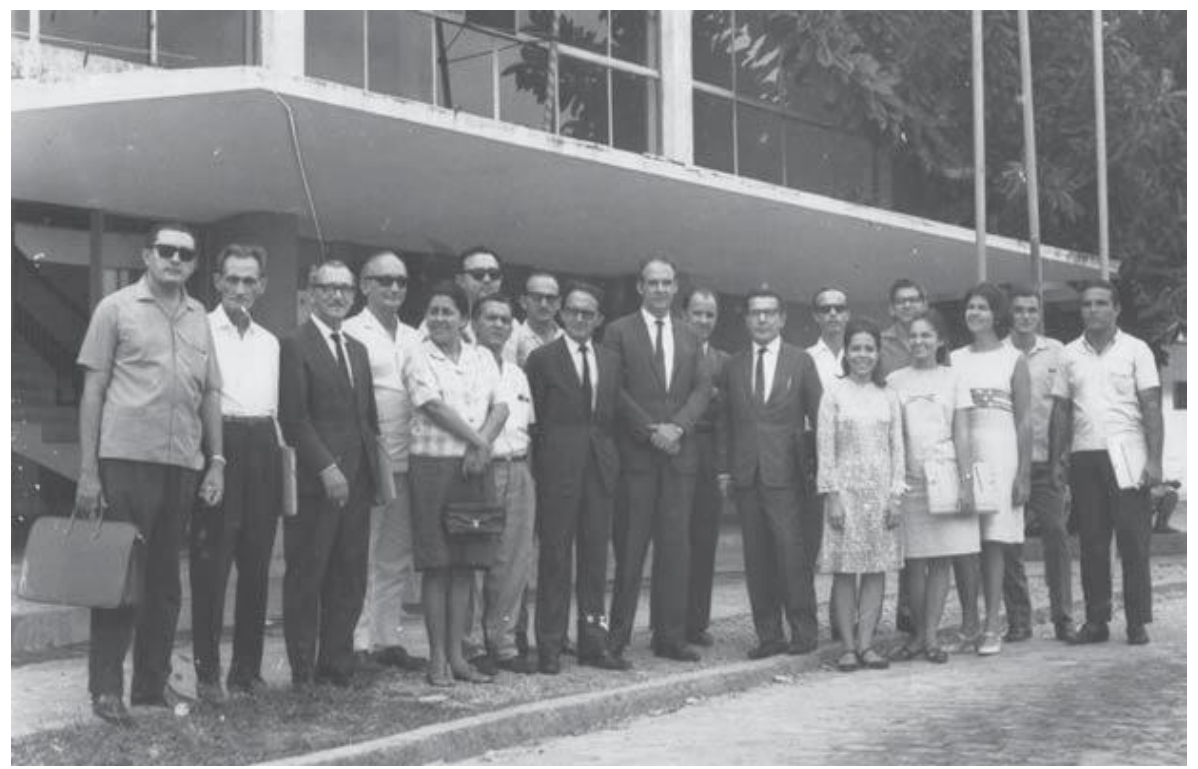

Nota: Texto publicado na Revista da Associação Brasileira de Educação Agrícola Superior em 1991 e atualizado em 2005.

Fonte: TAVARES, C. A. A formação de professores agrícolas na Universidade Federal Rural de Pernambuco: histórico, realidade e perspectivas. Anais da Academia Pernambucana de Ciência Agronômica, Recife, v. 2, p. 32-41, 2005.

O Ministério da Educação, de acordo com a Portaria Ministerial no 432/71 que instituiu duas formas emergenciais para formação de professores das chamadas "disciplinas específicas do ensino de $2^{\circ}$ grau", resolveu ofertar a formação de professores agrícolas em cursos de regimes intensivos e emergenciais, com a seguinte denominação: Esquemas I - diplomados em ciências agrárias. Esquemas II - técnicos agrícolas. No período de 1971 a 1982 a UFRPE, em convênio com a SUDENE, PRODEM - Programa de Desenvolvimento do Ensino Médio, PREMEN Programa de Expansão e Melhoria do Ensino, CENAFOR - Centro Nacional de Aperfeiçoamento de Pessoal para Formação Profissional e COAGRI - Coordenação de Ensino Agropecuário, formou no Esquema I, 191 professores agrícolas de diversas escolas agrícolas em todo o Brasil, num currículo que contemplava as disciplinas básicas, técnicas e pedagógicas. No Esquema II foram habilitados 28 técnicos agrícolas.

Em 1972 a UFRPE apresentou ao Conselho Federal de Educação o projeto referente ao curso de Licenciatura em Ciências Agrícolas. Tal projeto foi autorizado pelo Conselho através do 
parecer 320/72. No entanto, o curso foi extinto pela UFRPE em 1976 e seus 220 estudantes transferidos, após um plebiscito, para o curso de Agronomia. Apenas em 1983 a UFRPE aprovou a Licenciatura em Ciências Agrícolas perante o Conselho de Ensino, Pesquisa e Extensão, nos moldes que funciona hoje. Esta Licenciatura é oferecida para estudantes e diplomados dos cursos de Agronomia, Medicina Veterinária, Engenharia Florestal, Zootecnia, Engenharia de Pesca e Engenharia Agrícola, desde 1984.

Os principais motivos para oferta deste curso estão descritos, a seguir: 1) Implantação dos cursos de Engenharia de Pesca e Engenharia Florestal, em 1972. 2) Desejo dos profissionais das Ciências Agrárias de exercer o magistério. 3) A legislação obrigava a formação de licenciados para Agrônomos, Veterinários e Técnicos Agrícolas que atuavam nas escolas e colégios agrícolas, forçando o retorno à UFRPE para tal qualificação. 4) Outro importante motivo foi a experiência, bem sucedida, nos cursos de habilitação do magistério para Agrônomos e Veterinários que cursaram a parte pedagógica (TAVARES, 2005). Com esta Licenciatura, a UFRPE e seus colaboradores, passaram a contribuir, historicamente, com a área educacional agrícola, o desenvolvimento sustentável do meio rural e a valorização dos sujeitos camponeses. Passou a ser encarada como instituição formadora de recursos humanos, com capacidade crítica e emancipadora, atuando em vários espaços do campo brasileiro, em especial, no fortalecimento da agricultura familiar.

\section{Conhecendo a licenciatura em Ciências Agrícolas}

O curso de Licenciatura Plena em Ciências Agrícolas da UFRPE, popularmente conhecido por L.A, foi criado pela Resolução $n^{\circ}$ 12/70 do Conselho de Ensino e Pesquisa da UFRPE e autorizado pelo Conselho Federal de Educação através do Parecer no 320/72. O processo seletivo é organizado semestralmente pela coordenação do curso e tem a intenção de selecionar quarenta estudantes, através da realização de entrevistas, análise curricular e outros elementos definidos pela coordenação. Ocorre apenas para graduandos que tenham concluído o quarto período dos cursos de Agronomia, Engenharia Agrícola e Ambiental, Engenharia de Pesca, Engenharia Florestal, Medicina Veterinária, Zootecnia e os diplomados nestes cursos.

De acordo com o Projeto Político Pedagógico - PPP, o curso tem como objetivo geral formar educadores que contribuam com práticas educativas para ampliar os conhecimentos e o 
estabelecimento da convivência sustentável entre homem e natureza. A formação docente realizada pela L.A está centrada no compromisso social, visando articulações entre o conhecimento teórico e prático, colaborando com o contexto rural e a gestão do desenvolvimento local. Nesta Licenciatura, segundo o PPP, é assegurado o exercício da cidadania, prática social e formação de valores. Além disso, exalta-se a construção do conhecimento através da educação popular e a diversidade cultural, formando educadores que atuem como agentes da transformação.

O Licenciado em Ciências Agrícolas tem como campo de atuação os seguintes espaços: 1) Estabelecimentos de ensino fundamental, médio e de educação profissional. 2) Escolas agrícolas e/ou agrotécnicas. 3) Agências de desenvolvimento. 4) Organizações não-governamentais. 5) Cooperativas e associações. 6) Órgãos públicos e privados. Além disso, o profissional de educação agrícola pode atuar nas seguintes áreas do conhecimento: 1) Ciências Agrárias. 2) Educação, educação do campo, educação rural. 3) Agricultura familiar. 4) Educação ambiental. 5) Agricultura sustentável. 6) Desenvolvimento local. O trabalho desse educador agrícola não se limita à sala de aula. Faz-se extremamente necessária a preocupação com pesquisas científicas e extensão. Seu trabalho repercute no mundo agrícola, construindo conhecimentos necessários ao agricultor brasileiro de forma diferenciada, considerando as reflexões em relação à ciência, tecnologia, consciência ambiental e sustentabilidade.

Segundo o Projeto Político Pedagógico, a matriz curricular do curso atende os seguintes princípios: 1) Articulação dos diferentes âmbitos do conhecimento profissional. 2) Interação, comunicação e desenvolvimento da autonomia intelectual e profissional. 3) Disciplinaridade e interdisciplinaridade. 4) Articulação entre formação comum e formação específica. 5) Articulação dos conhecimentos educacionais e pedagógicos que fundamentam a ação educativa.

Para uma melhor compreensão didática, dividimos a matriz curricular da Licenciatura em Ciências Agrícolas, em linhas horizontais e linhas verticais. As linhas horizontais apresentam quatro blocos de disciplinas que compreendem as diversas formações do curso. As linhas verticais estão divididas em seis períodos, compostas pelas disciplinas que deverão ser cursadas. Daremos ênfase às linhas horizontais, abordando os blocos de formação. No primeiro bloco temos as disciplinas de formação profissional específica. Essas disciplinas estão relacionadas à produção animal e vegetal, cursadas nos cursos de origem e apresentadas à coordenação da L.A, num total de 1185 horas. Neste bloco, os estudantes de Medicina Veterinária não tem acesso às 
disciplinas de produção vegetal, por não fazer parte do curso de origem. Esta pode ser uma fragilidade verificada na formação profissional deste licenciando.

O segundo bloco é composto pelas disciplinas de formação profissional pedagógica, oferecidas no curso de L.A, num total de 630 horas de atividades. Ele é muito importante para formação crítica e emancipadora dos estudantes, em sua grande maioria, vinculados a cursos tecnicistas. Esse bloco de formação pedagógica é responsável pelas disciplinas que agregam valor na formação dos educadores, desenvolvendo a criticidade, o compromisso social e a inserção do estudante na realidade sócio educacional, apresentando uma formação humanística que fortaleça os sujeitos do campo.

O terceiro bloco é composto por uma carga horária de 810 horas, diretamente relacionadas às práticas de ensino e aos estágios supervisionados. As disciplinas são cursadas a partir do primeiro período e segue a mesma lógica de divisão do primeiro bloco. Os estudantes oriundos dos cursos de produção animal farão seus estágios e práticas de ensino apenas em ambientes relacionados a este tipo de produção. O mesmo ocorre para os estudantes dos cursos de produção vegetal. As práticas de ensino e os estágios curriculares têm a intenção de articular teoria e prática, desenvolvendo competências profissionais ligadas ao exercício da cidadania e prática social, descrito no Projeto Político Pedagógico de curso.

Por fim, o quarto bloco, com 210 horas de carga horária, está relacionado às atividades complementares. Tais atividades compreendem tudo aquilo que o estudante pode fazer fora do seu programa de disciplina, por exemplo, a participação em eventos, seminários e congressos. Para essas atividades o curso desenvolve uma semana de interação conhecida como "Semana de Culminância”, atendendo alguns princípios presentes na matriz curricular, em especial, a integração dos conteúdos trabalhados nos semestres, a partir da interdisciplinaridade e trabalho coletivo desenvolvido nas disciplinas de prática de ensino.

A Semana de Culminância é essencial no desenvolvimento das turmas e estudantes da Licenciatura em Ciências Agrícolas. As trocas de experiências mútuas enriquecem o evento e a formação dos sujeitos envolvidos na utilização dos recursos didáticos e metodológicos. A semana tem suas apresentações realizadas de forma decrescente, por período. O sexto período é o primeiro a apresentar suas atividades. Em seguida, o quinto, e assim por diante. Tais apresentações trabalham com diversas linguagens, dentre elas: teatro, música e literatura de cordel. A seguir, a matriz curricular da Licenciatura em Ciências Agrícolas: 
Figura 3 - Matriz curricular do curso de L.A em 2015.

\begin{tabular}{|c|c|c|c|c|c|}
\hline $\begin{array}{c}1^{\circ} \\
\text { Disciplinas } \\
\text { Relacionadas com } \\
\text { PRODUÇÃO } \\
\text { ANIMAL } \\
\text { OU } \\
\text { PRULUCÃU } \\
\text { VEGETAL } \\
195 \mathrm{~h} \\
195 \mathrm{~h}\end{array}$ &  & $\begin{array}{c}3^{\circ} \\
\text { Disciplinas } \\
\text { Relacionadas com } \\
\text { PRODUCCÃO } \\
\text { ANIMAL } \\
\text { OU } \\
\text { PRULUC̃OA } \\
\text { VEGETAL } \\
195 \mathrm{~h} \\
195 \mathrm{~h}\end{array}$ & $\begin{array}{c}4^{\circ} \\
\text { Disciplinas } \\
\text { Relacionadas com } \\
\text { PRODUÇÃO } \\
\text { ANIMAL } \\
\text { OU } \\
\text { PRUUUC̃̃U } \\
\text { VEGETAL } \\
195 \mathrm{~h} \\
195 \mathrm{~h}\end{array}$ & 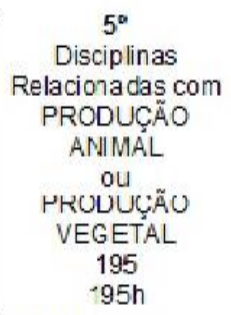 & $\begin{array}{c}6^{\circ} \\
\text { Disciplinas } \\
\text { Relacionadas com } \\
\text { PRODUÇÄO } \\
\text { ANIMAL } \\
\text { OU } \\
\text { PRULUC̈ÃO } \\
\text { VEGETAL } \\
210 \mathrm{~h} \\
210 \mathrm{~h}\end{array}$ \\
\hline \multicolumn{6}{|c|}{ Sub-total $01=1185 \mathrm{~h}-$ Formação Profissional Espećfica } \\
\hline $\begin{array}{c}\text { Introd. à Ps. } \\
\text { Educacicnal } \\
60 \mathrm{~h}\end{array}$ & $\begin{array}{c}\text { Ps. Co } \\
\text { Desenvolvimento } \\
60 \mathrm{~h}\end{array}$ & $\begin{array}{c}\text { Ps. Da } \\
\text { Aprendizagem } \\
60 \mathrm{~h} \\
\end{array}$ & $\begin{array}{c}\text { Didática } \\
\text { 6ah }\end{array}$ & $\begin{array}{l}\text { Metodolagia } \\
\text { Cnsino Agrícola } \\
90 \mathrm{~h} \\
\end{array}$ & - \\
\hline $\begin{array}{c}\text { Fund. Fil., Hist. e } \\
\text { Soc. da Educação } \\
\text { Agrícola } \\
60 \mathrm{~h} \\
\text { Educação Agrícola } \\
\text { e } 3 o c i e d a d e \text { Rural } \\
60 \mathrm{~h} \\
180 \mathrm{~h}\end{array}$ & $\begin{array}{c}\text { Estr. e Func. Da } \\
\text { Ed. Brasileira } \\
60 \mathrm{~h}\end{array}$ & $\begin{array}{c}\text { Estr. e Func. Do } \\
\text { Ens. Agrícola } \\
60 \mathrm{~h}\end{array}$ & $\begin{array}{c}\text { Gestão de } \\
\text { Unidades } \\
\text { Educativas } \\
60 \mathrm{~h} \\
- \\
120 \mathrm{~h}\end{array}$ & $90 \mathrm{~h}$ & - \\
\hline \multicolumn{6}{|c|}{ Sub-total $02=630$ h Formação Profissional Pe dagógica } \\
\hline $\begin{array}{c}\text { Prática de Ensino: } \\
\text { Metodnlojias } \\
\text { Participativas } \\
45 \mathrm{~h}\end{array}$ & $\begin{array}{c}\text { Prática de Ensino: } \\
\text { Planej.jamento } \\
60 \mathrm{~h}\end{array}$ & $\begin{array}{c}\text { Prática de Ensino: } \\
\text { Gestãn } \\
75 \mathrm{~h}\end{array}$ & $\begin{array}{c}\text { Prática de Ensino: } \\
\text { Sistemas de } \\
\text { Produção } \\
\text { Agropecuária } \\
75 \mathrm{~h}\end{array}$ & $\begin{array}{c}\text { Prática de Ensino: } \\
\text { Prodıção Animal e } \\
\text { Agroindústria I } \\
75 \mathrm{~h} \\
\text { Prática de Ensino: } \\
\text { Produção Vegetal } \\
\text { e Agroindústria I } \\
75 \mathrm{~h} \\
\text { Fstágio } \\
\text { Curricular II } \\
\text { '05h }\end{array}$ & $\begin{array}{c}\text { Prática de Ensino: } \\
\text { Prodıçã̃o Animal e } \\
\text { Agrondústria II } \\
75 \mathrm{~h} \\
\text { Prática de Ensino: } \\
\text { Produક̧ão Vegetal } \\
\text { e Agroindústria II } \\
75 \mathrm{~h} \\
\text { Fstágio } \\
\text { Curricular III } \\
210 \mathrm{~h}\end{array}$ \\
\hline $45 \mathrm{~h}$ & $\begin{array}{c}60 \mathrm{~h} \\
\text { Sub-total } 03\end{array}$ & $\begin{array}{c}75 \mathrm{~h} \\
\text { Oh de Prática }\end{array}$ & $\begin{array}{c}165 \\
\text { e de Estág }\end{array}$ & $\begin{array}{c}\text { 80h } \\
\text { supervisionado }\end{array}$ & $285 \mathrm{~h}$ \\
\hline $\begin{array}{c}\text { Ativid. } \\
\text { Complm. } \\
30 \mathrm{~h}\end{array}$ & $\begin{array}{c}\text { Ativid. } \\
\text { Complom. } \\
30 \mathrm{~h}\end{array}$ & $\begin{array}{c}\text { Ativid. } \\
\text { Complem. } \\
30 \mathrm{~h}\end{array}$ & $\begin{array}{c}\text { Ativid. } \\
\text { Complem. } \\
30 \mathrm{~h}\end{array}$ & $\begin{array}{c}\text { Ativid. } \\
\text { Complem. } \\
45 \mathrm{~h}\end{array}$ & $\begin{array}{c}\text { Ativid. } \\
\text { Complem } \\
45 \mathrm{~h} .\end{array}$ \\
\hline $30 \mathrm{~h}$ & $30 \mathrm{~h}$ & $30 \mathrm{~h}$ & $30 \mathrm{~h}$ & $45 \mathrm{~h}$ & $45 \mathrm{~h}$ \\
\hline
\end{tabular}

Fonte: Coordenação do curso de Licenciatura em Ciências Agrícolas da UFRPE.

Verificamos que a Licenciatura em Ciências Agrícolas da UFRPE mantém suas particularidades de acesso, organização pedagógica e estrutura curricular. Diferencia-se dos demais cursos em outras universidades brasileiras e mesmo na UFRPE, ressaltando a organização em seis períodos e uma carga horária de 2.835 horas, entre formação profissional, pedagógica, prática de ensino, estágio supervisionado e atividades complementares. Realiza seleção semestral para entrada de quarenta estudantes diplomados ou cursando até o quarto período de Agronomia, Engenharia Agrícola e Ambiental, Engenharia de Pesca, Engenharia Florestal, Medicina Veterinária e Zootecnia. Seu foco está centrado na agricultura familiar, orgânica e agroecológica, reconstruindo conceitos científicos e práticas abordadas nos cursos de origem. Tais posturas e 
direcionamentos podem contribuir com a formação crítica deste licenciando. As conversas com os sujeitos do curso dão conta de possíveis reformulações do Projeto Político Pedagógico, inclusive, com possibilidades de mudanças no processo seletivo e na estrutura curricular da Licenciatura em Ciências Agrícolas da UFRPE.

\section{A formação de professores do ensino agrícola: uma breve discussão}

A discussão sobre formação de professores do ensino agrícola no Brasil é fortalecida nas décadas de 1970, 1980 e 1990, a partir da implantação dos cursos de licenciatura. O desenvolvimento das pesquisas em relação à formação de professores dialogou com o movimento de profissionalização docente e os debates em relação à escola, garantindo a legitimidade da profissão (TARDIF, 1999).

No Brasil, em especial, a partir da década de 1990, novos enfoques e paradigmas foram defendidos para compreender a formação de professores do ensino agrícola, suas práticas pedagógicas, histórias, memórias e identidades. As pesquisas desenvolvidas destacam a importância dos educadores, os aspectos históricos e profissionais, a formação crítica e emancipadora além dos espaços escolares e institucionais. Segundo Perrenoud (2001), numa época de tantas mudanças, a questão da formação de professores vem assumindo posição de urgência nos espaços escolares.

Os cursos de formação de professores precisam superar o déficit histórico em relação à formação pedagógica. Segundo (PEREIRA, 1999) alguns cursos de licenciatura trabalham na lógica da mera transmissão de conhecimentos. Os conteúdos específicos precedem os pedagógicos, sem a mínima articulação. No intuito de defender a importância da formação de professores, em especial, das ciências agrícolas, decidimos apresentar a tabela abaixo, com os saberes docentes defendidos por (TARDIF, 2004, p. 63): 
Tabela 1 - Saberes docentes

\begin{tabular}{|c|c|c|}
\hline Saberes dos professores & Fontes sociais de aquisição & $\begin{array}{l}\text { Modos de integração no } \\
\text { trabalho docente }\end{array}$ \\
\hline Saberes pessoais dos professores. & $\begin{array}{l}\text { A família, o ambiente de vida, a } \\
\text { educação no sentido lato, etc. }\end{array}$ & $\begin{array}{l}\text { Pela história de vida e pela } \\
\text { socialização primária. }\end{array}$ \\
\hline $\begin{array}{lll}\text { Saberes } & \text { provenientes } & \text { da } \\
\text { formação escolar anterior. } & \end{array}$ & $\begin{array}{l}\text { A escola primária e secundária, } \\
\text { os estudos pré-secundários não } \\
\text { especializados, etc. }\end{array}$ & $\begin{array}{l}\text { Pela formação e pela } \\
\text { socialização pré-profissionais. }\end{array}$ \\
\hline $\begin{array}{l}\text { Saberes provenientes para } \\
\text { formação profissional para o } \\
\text { magistério. }\end{array}$ & $\begin{array}{l}\text { Os estabelecimentos de formação } \\
\text { de professores, os estágios, os } \\
\text { cursos de reciclagem, etc. }\end{array}$ & $\begin{array}{l}\text { Pela formação e pela } \\
\text { socialização profissionais nas } \\
\text { instituições de formação de } \\
\text { professores. }\end{array}$ \\
\hline $\begin{array}{l}\text { Saberes provenientes dos } \\
\text { programas e livros didáticos } \\
\text { usados no trabalho. }\end{array}$ & $\begin{array}{l}\text { A utilização de "ferramentas" } \\
\text { dos professores: programas, } \\
\text { livros didáticos, cadernos de } \\
\text { exercícios, fichas, etc. }\end{array}$ & $\begin{array}{l}\text { Pela utilização das "ferramentas" } \\
\text { de trabalho, sua adaptação às } \\
\text { tarefas. }\end{array}$ \\
\hline $\begin{array}{l}\text { Saberes provenientes da } \\
\text { própria } \\
\text { experiência } \\
\text { profissão, na sala de aula e na } \\
\text { escola. }\end{array}$ & $\begin{array}{l}\text { A prática do ofício na escola e na } \\
\text { sala de aula, a experiência dos } \\
\text { pares, etc. }\end{array}$ & $\begin{array}{l}\text { Pela prática do trabalho e pela } \\
\text { socialização profissional. }\end{array}$ \\
\hline
\end{tabular}

Fonte: TARDIF, M. Los saberes del docente y su desarrollo profesional. Madrid: Narcea, 2004. p. 63.

Nesta tabela, o autor procura abordar os saberes necessários à vida profissional do professor. A forma diversificada de entender os saberes docentes e as relações entre eles, é reafirmada por (GAUTHIER, 2006, p. 28): "é muito mais pertinente conceber o ensino como a mobilização de vários saberes que formam uma espécie de reservatório no qual o professor se abastece para responder as exigências especificas de sua situação concreta de ensino". Percebemos o quanto é desafiador para os docentes trabalhar o saber científico com um público composto por vários segmentos sociais. Não é possível executar as mesmas práticas docentes, com formas de expressão, crenças, valores, expectativas e contextualização sócio-familiar de estudantes tão diversificadas (DELIZOICOV; ANGOTTI; PERNAMBUCO, 2002). Nesse contexto, concordamos com as atuais pesquisas sobre formação de professores. Elas nos revelam a importância de analisar a prática pedagógica como algo essencial, contrária às ideias de separação entre formação teórica e prática, embora reconheça a complexidade da associação entre práticas educativas e cotidianas. Segundo (TARDIF; LESSARD; LAHAYE, 1991, p. 219) "Quanto mais um saber é desenvolvido, formalizado, sistematizado, como acontece com as ciências e os saberes contemporâneos, mais se revela longo e complexo o processo de aprendizagem que exige, por sua vez, uma formalização e uma sistematização adequada”. 
Tardif, Lessard e Lahaye (1991), reconhecem a importância dos saberes cotidianos de educadores e educandos. Defendem a construção coletiva do conhecimento científico e ações que envolvem a utilização das tecnologias e práticas pedagógicas em ambientes formais ou informais de aprendizagens. A produção crítica do conhecimento nos espaços escolares pode estar atrelada à construção dos valores da convivência social, valorização da realidade de vida dos sujeitos e suas práticas cotidianas. Para Moreira e Candau (2005, p. 23):

É necessário um destaque a necessidade de se pensar uma formação continuada que valorize tanto a prática realizada pelos docentes no cotidiano da escola quanto o conhecimento que provém das pesquisas realizadas na Universidade, de modo a articular teoria e prática na formação e na construção do conhecimento profissional do professor.

Acreditamos que a Licenciatura em Ciências Agrícolas da UFRPE atende, em sua maior parte, a formação de professores para lidar com a prática docente. No entanto, os campos de trabalho estão cada vez menores e, quando existem, apresentam exigências profissionais que não contemplam os licenciados. Nesse estudo, verificamos ainda a dificuldade estrutural entre a formação específica (cursos de origem) e a formação pedagógica (curso de L.A). Educadores e educandos percebem a necessidade de mudanças na estrutura curricular, com o intuito de aprimorar a formação de professores na Licenciatura em Ciências Agrícolas. Em relação à tal formação, importante reafirmar que suas referências consideram as questões individuais e coletivas desses sujeitos (NÓVOA, 1992), pautada na produção crítica e emancipadora do conhecimento, preocupada com o desenvolvimento de ferramentas educativas e novas metodologias capazes de preparar educadores e educandos para compreensão e transformação da sociedade (SACRISTÁN; PÉREZ GÓMEZ, 1998).

\section{Considerações finais}

Neste artigo, nossa intenção foi conhecer um pouco a história da Universidade Federal Rural de Pernambuco. Foi possível ainda conhecer as bases históricas da educação agrícola na UFRPE, em especial, a formação de professores, a constituição da Licenciatura em Ciências Agrícolas em 1984 e suas demandas de atendimento às Escolas Agrícolas do nordeste brasileiro. A partir de breve análise do Projeto Político Pedagógico de curso, entrevistas e levantamento histórico realizado acerca da formação de professores do ensino agrícola, foi possível conhecer a matriz curricular da L.A. Ele apresenta um caráter extremamente crítico na defesa de cidadãos 
que atuem, em especial, nas instituições de ensino básico e/ou instituições de ensino técnico, agências de desenvolvimento, órgãos não governamentais, cooperativas e demais espaços agrícolas.

Importante registrar o empenho dos sujeitos, individuais e coletivos, na defesa de currículos que dialoguem com a identidade das comunidades camponesas. Essas conquistas coletivas podem assegurar espaços democráticos e exercícios de autonomia, contribuindo na contextualização dos educandos e no reconhecimento de suas práticas educativas. Valoriza-se a produção do saber, considerando as áreas de conhecimentos, rompendo com o processo de disciplinarização dos conteúdos, de responsabilidade individual dos educadores. Defendemos na formação dos sujeitos educadores, o compromisso coletivo com a transformação social, sendo agentes promotores de uma educação popular que permita superar a precariedade dos muitos espaços campesinos. Urgente ainda: 1) a implementação de políticas de valorização desses trabalhadores, através do cumprimento da Lei do Piso Nacional para os profissionais do magistério, 2) enfrentar a altíssima rotatividade dos docentes nas escolas do campo, 3) formação continuada dos educadores, considerando as especificidades da educação do campo. Concluímos que a Licenciatura em Ciências Agrícolas da UFRPE no trabalho com a reconstrução das ideias e conceitos advindos dos diversos cursos de origem dos licenciados, deve continuar aprofundando os debates acerca da interdisciplinaridade, a agricultura familiar, orgânica, agroecológica e o desenvolvimento sustentável.

Por fim, salientamos que a produção do conhecimento pautada nos dados coletados e nas observações efetuadas não são isentas de valores. A construção crítica e coerente do saber não é neutra. Assim, a história pessoal dos autores permeou todo o desenvolvimento desse trabalho. Esperamos, dessa forma, estimular a produção de leituras e reflexões que contemplem a formação dos educadores/as do campo. Nesse processo de construção histórica prevaleceu o respeito às diferenças e a valorização da identidade cultural dos sujeitos sociais envolvidos neste trabalho, propondo uma educação inclusiva, questionadora e democrática, presente em inúmeras escolas do campo e diversas experiências de educação popular espalhados por esse Brasil afora. 


\section{Referências}

ARAÚJO, B. M. de. Educação e poder: o ensino superior agrícola em Pernambuco nas décadas de 1930 e 1940. 2013. Dissertação (Mestrado em História Social da Cultura) - Programa de Pós-graduação em História, Universidade Federal Rural de Pernambuco, Recife, 2013.

BRASIL. Ministério da Educação. Portaria Ministerial no 432/71. Instituiu formas emergenciais para formação de professores das chamadas "disciplinas específicas do ensino de $2^{\circ}$ grau". Brasília, 1971.

DELIZOICOV, D.; ANGOTTI, J. A.; PERNAMBUCO, M. M. Temas de ensino e escola. In: ANGOTTI, J. A.; PERNAMBUCO, M.M. Ensino de ciências: fundamentos e métodos. São Paulo: Cortez, 2002.

GAUTHIER, C. et al. Por uma teoria da pedagogia: pesquisas contemporâneas sobre o saber docente. 2. ed. Ijuí: Editora Unijuí, 2006.

GIL, A. C. Métodos e técnicas de pesquisa social. 5. ed. São Paulo: Atlas, 1999.

MINAYO, M. C. S. O desafio do conhecimento: pesquisa qualitativa em saúde. 3. ed. São Paulo: Hucitec/Abrasco, 1994.

MOREIRA, A. F. B.; CANDAU, V. M. Educação escolar e cultura(s): construindo caminhos. In: EDUCAÇÃO como exercício de diversidade. Brasília: UNESCO, MEC, ANPEd, 2005.

NÓVOA, Antônio. Formação de professores e formação docente. In: NÓVOA, Antônio. Os professores e a sua formação. Lisboa: Publicações Dom Quixote, 1992.

PEREIRA, J. E. D. A licenciatura e as novas políticas educacionais para a formação docente. Educação e Sociedade, Campinas, v. 20, n. 68, p. 109-125, 1999.

PERRENOUD, P. A ambigüidade dos saberes e da relação com o saber na profissão de professor. PERRENOUD, P. Ensinar: agir na urgência, decidir na incerteza. Porto Alegre: Artmed, 2001. p. 135193.

SACRISTÁN, J. G.; PÉREZ GÓMEZ, A. Compreender e transformar o ensino. Porto Alegre: Artes Médicas, 1998.

TAVARES, C. A. A formação de professores agrícolas na Universidade Federal Rural de Pernambuco: histórico, realidade e perspectivas. Anais da Academia Pernambucana de Ciência Agronômica, Recife, v. 2, p. 32-41, 2005.

TARDIF, Maurice; LESSARD, Claude; LAHAYE, Louise. Os professores face ao saber; esboço de uma problemática do saber docente. Teoria \& Educação, Porto Alegre, v. 1, n. 4, p. 215-233, 1991.

TARDIF, Maurice. Saberes profissionais dos professores e conhecimentos universitários. Rio de Janeiro: PUC, 1999.

TARDIF, Maurice. Los saberes del docente y su desarrollo profesional. Madrid: Narcea, 2004. 
126 SANTOS, Ramofly Bicalho; SANTOS, Ozias Henrique. Conhecendo a licenciatura em Ciências Agrícolas da UFRPE: aspectos da formação de professores.

Ramofly Bicalho Santos - Universidade Federal Rural do Rio de Janeiro - UFRRJ. Seropédica | RJ | Brasil. Contato: ramofly@gmail.com

Ozias Henrique Santos - Universidade Federal Rural de Pernambuco - UFRPE. Carpina | PE | Brasil. Contato: ozias_henrique@hotmail.com

Artigo recebido em: 14 mar. 2016 e aprovado em: 20 mar. 2017.

Quaestio, Sorocaba, SP, v. 19, n. 1, p. 111-126, abr. 2017. 